\title{
Effect of COVID-19 Pandemic on Older New York City Residents Living at Home
}

\author{
Abigail R. Greenleaf ${ }^{1,2}\left(\right.$ Monique Millington $^{1} \cdot{\text { Kiana } \text { Chan }^{3} \cdot \text { Melissa Reyes }}^{1} \cdot$ Shannon M. Farley ${ }^{1} \cdot$ Andrea Low $^{1,3}$. \\ David Hoos ${ }^{1} \cdot$ Wafaa M. El-Sadr ${ }^{1,3}$
}

Accepted: 18 December 2021 / Published online: 20 January 2022

(c) The Author(s), under exclusive licence to Springer Science+Business Media, LLC, part of Springer Nature 2022

\begin{abstract}
To describe effects of the COVID-19 pandemic on older adults living in non-institutionalized settings in New York City (NYC) we used random digit dial sampling of landlines phones to sample then interview residents 70 years and older in NYC from December 2020-March 2021. Socio-demographic, health characteristics and effects of the COVID-19 pandemic were solicited. Of 676 respondents, the average age was 78, 60\% were female, and $63 \%$ had ever been tested for SARS-CoV-2, with $12 \%$ testing positive. Sixty-three percent of respondents knew someone who had been diagnosed with COVID-19 and $51 \%$ reported knowing at least one person who had died from COVID-19. Eight percent of respondents reported sometimes or often not having enough to eat, with $31 \%$ receiving food from a food pantry program. Significantly more Latinx respondents (24\%) reported a positive SARS-CoV-2 test, whereas $17 \%$ of those of another race, $8 \%$ of white, and $7 \%$ of Black respondents had a positive COVID-19 test $(p<0.01)$. Forty-three percent of Black and $43 \%$ of Latinx respondents reported using a food pantry during COVID-19 pandemic, compared to 35\% of respondents of another race and ethnicity and $18 \%$ of whites $(\mathrm{p}<0.01)$. Twenty-nine percent of Latinx respondents screened for depression compared to $15 \%$ among all other races $(\mathrm{p}=0.04)$. The COVID-19 pandemic has substantial health and social effects on older New Yorkers living in community settings, and experiences differed by race and ethnicity. Beyond older adults in congregate settings, those living at home have experienced wide-ranging effects of COVID-19, necessitating tailored interventions.
\end{abstract}

Keywords COVID-19 $\cdot$ Older adults $\cdot$ Social determinants of health $\cdot$ Health inequities

\section{Background}

With $80 \%$ of COVID-19 deaths reported among those over 65 years of age in the United States, the disproportionate effect on older adults is well-established. [1]) Heightened vulnerability among older adults has been documented worldwide; [2] motivating development of specific guidance for this population [3, 4]. However, COVID-19 related effects have been studied largely among older individuals

Abigail R. Greenleaf

arg2177@cumc.columbia.edu

1 ICAP at Columbia University, Columbia University Mailman School of Public Health, New York, NY, USA

2 Department of Population and Family Health, Columbia University Mailman School of Public Health, 60 Haven Avenue, Room B1-115, New York, NY 10023, USA

3 Department of Epidemiology, Columbia University Mailman School of Public Health, New York, NY, USA living in congregate settings such as nursing homes and other long-term facilities [5] and less attention has been paid to those living at home. Furthermore, research has focused more on mortality than morbidity among such individuals. [6] This has resulted in a paucity of information regarding the effects of the COVID-19 pandemic on mental health, economic well-being and social relations among older adults living at home.

Older adults aged 65 and above comprise 13\% (1.1. million) of the population of New York City (NYC), with projections estimating that the number of older New Yorkers will increase $40 \%$ by 2040 and become more ethnically and racially diverse [7]. The majority of older New Yorkers currently live at home, with only $3 \%$ residing in a nursing home [7].

The disproportionate impact of the COVID-19 pandemic in the United States on people of certain racial and ethnic groups was evident since the early days of the pandemic, with Black, Latinx and American Indians being hospitalized 
Fig. 1 SILVER study enrollment flowchart

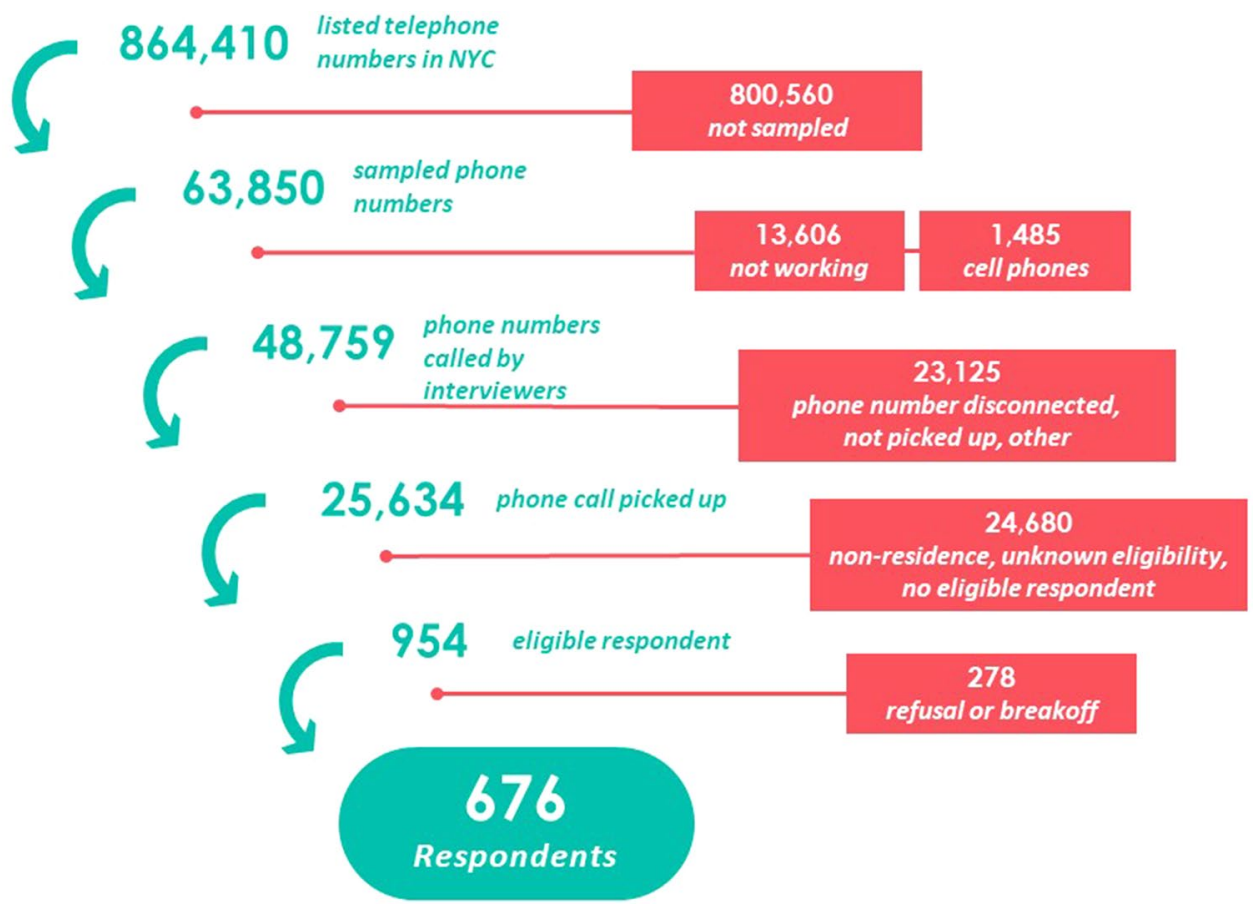

and dying at a higher rate than white persons [8]. Racial and ethnic COVID-19 inequities in the United States are driven by differences in social determinants of health including healthcare access and use, occupation, education, income, housing and discrimination [9]. Whether such inequities manifest among older New Yorkers and how they manifest remain unclear.

We conducted a survey, the SARS-CoV-2 Impact on Lives and Views of Elderly Residents (SILVER) study, among a random sample of older (aged 70 and above) community-dwelling NYC residents to gather information on the direct and indirect effects of COVID-19 pandemic on their health and well-being.

\section{Methods}

We used a sample frame consisting of 864,410 listed telephone numbers in NYC to reach non-institutionalized residents 70 year or older with a landline phone (see Fig. 1). From this frame, a stratified random sample of 63,850 telephone numbers was selected. The five strata used correspond to the five NYC boroughs and a sixth stratum included the 18 zip codes with the highest COVID-19 case counts as of October 2020. Within a given stratum, all landline telephone numbers had the same probability of selection.

Interviewers used a computer-assisted telephone interview (CATI) software system to make the calls. To encourage participation, calls took place seven days a week at a variety of times. Interviewers made a minimum of three attempts to reach a household and interview an eligible individual for each telephone number in the sample frame. Any adult (70 years of age or older) residing in the household was eligible. If there were two or more eligible household members, we used the "most recent birthday method", in which the interviewer asked to speak with the adult 70 years or older living in the household who had the most recent birthday. Interviewers administered verbal consent to the individual selected.

Interviews were conducted between December 2020 and March 2021 in English, Spanish, Mandarin, Cantonese, and Haitian Creole. Whereas bilingual interviewers conducted Spanish-language interviews, the other three languages were administered through a simultaneous third-party translator. Respondents who completed the survey received either a $\$ 10$ gift card or check in the mail for their time. The Columbia University Irving Medical Center and Research Triangle Institute institutional review boards approved the protocol and data collection tools.

\section{Measurements}

We collected information on sociodemographic and health characteristics including age, gender (male, female), borough of residence (Bronx, Brooklyn, Manhattan, Queens and Staten Island), marital status (married or living together, divorced, widowed, separated and never married), household income $(<\$ 25,000, \$ 25,000$ to $\leq \$ 50,000, \$ 50,000$ to $\leq 100,000, \geq 100,000$ ), country of birth (born in the US, born in another country), educational attainment (less than 
high school, high school diploma/GED, some college/University, College/University degree), employment status (currently working, not currently working) and race and ethnicity. Respondents were asked if they were Hispanic or Latino/a, then were asked to report their race. These two questions were used to create the race and ethnicity variable, with those reporting Hispanic/Latino/a ethnicity being excluded from the other three race categories (white, Black, and "identified in another way"). The fourth category "identified in another way" is compromised of those who did not identify as Hispanic/Latino/a, white or Black. This includes but is not limited to anyone who is multi-racial as well as Asian.

To describe their health status, we asked respondents to self-rate their health (excellent, very good, good, fair and poor). We also asked about 14 co-existing health conditions with responses categorized into three groups: none, one, or two or more health conditions.

COVID-19 related modules included questions regarding individual effects of the COVID-19 pandemic, COVID19 testing and diagnosis, and COVID-19 knowledge, attitudes and practices. Likert scale questions offered a 4-point scale except one question which offered a middle "about the same amount" option. Reference periods for the questions included "since COVID-19 pandemic started" and "in the last 3 months". A multi-generational household was defined as a respondent currently living with their children or grandchildren. The validated Patient Health Questionnaires[10] (PHQ-2) and Generalized Anxiety Disorders 2-item (GAD-2)[11] were used to screen for depression and anxiety symptoms. A score of 3 or greater on the PHQ-2 screener was considered consistent with evidence of depression and a score of 3 or more on GAD-2 consistent with anxiety.

\section{Statistical Analyses}

All results presented in the analyses are weighted: using the design-based weight as a starting point, the final analytic weight also included eligibility adjustment, nonresponse adjustments and post-stratification adjustments. We tested for differences in COVID-19 pandemic related experiences and effects by race and ethnicity using the Rao-Scott chi ${ }^{2}$ test (SAS version 9.4). The datasets generated during and/ or analyzed during the current study are available from the corresponding author on reasonable request.

\section{Results}

A total of 720 respondents were enrolled, with the analytic sample including 676 respondents, among whom 549 completed the survey in English, 29 in Spanish, and 98 in
Haitian Creole, Mandarin or Cantonese. Table 1 shows key demographics of the study population overall and by racial and ethnic groupings (Black; Latinx; white; Those of another race and ethnicity). The average age of respondents was 78.4 years, the median 76.6 years (standard error: 75.6-77.6) and 60\% were female. Twenty-nine percent resided in Queens, 28\% Brooklyn, 23\% Manhattan, 14\% Bronx and $7 \%$ Staten Island. White respondents comprised $45 \%$ of respondents, followed by $21 \%$ Black, $20 \%$ Latinx and $14 \%$ who identified in another way. Thirty-five percent reported less than $\$ 25,000$ annual income, $44 \%$ were married, $45 \%$ had a college degree or higher, $63 \%$ had two or more health conditions, and almost half $(52 \%)$ reported being born outside the US. Thirty-eight percent lived in a multi-generational household and $10 \%$ reported currently working.

Latinx respondents were significantly younger compared to other race and ethnicities: only $26 \%$ of Latinx respondents were over 80 , compared to $39 \%$ of those of another race, $41 \%$ of Blacks, and $42 \%$ of whites $(p=0.03)$. White respondents were more likely to report a high income than other race and ethnicities: $26 \%$ of white respondents had an annual income of greater than $\$ 100,000$, compared to $12 \%$ of those of another race, $7 \%$ of Black and $2 \%$ of Latinx respondents $(p<0.01)$. White respondents were also more likely to have higher educational attainment, with 59\% reporting a college/university degree compared to $51 \%$ of those of another race, $39 \%$ of Black and $15 \%$ of Latinx respondents $(p<0.01)$. Immigration also differed by race and ethnicity: $27 \%$ of whites were not born in the US, compared to $54 \%$ of Black, $70 \%$ of Latinx respondents, and $76 \%$ of those of another race and ethnicity $(p<0.01)$. Finally, $56 \%$ of Black respondents reported living in multi-generational household, compared to $52 \%$ of those of another race, $44 \%$ of Latinx and $24 \%$ of white respondents $(p=0.01)$.

\section{Experience with COVID-19}

Overall, 63\% of respondents reported that they had ever been tested for SARS-CoV-2, and $12 \%$ had tested positive (Table 2). Sixty-three percent of respondents knew at least one person who had been diagnosed with COVID-19 and $51 \%$ reported knowing at least one person who had died from COVID-19.

Significantly more Latinx respondents (24\%) reported a positive SARS-CoV-2 test, whereas $17 \%$ of those of another race, $8 \%$ of white, and $7 \%$ of Black respondents had a positive covid test $(p<0.01)$. The number of people who died from COVID-19 that respondents personally knew differed by race and ethnicity with $22 \%$ of those of another race knowing 5 or more people, compared to $14 \%$ of Latinx, $13 \%$ of Black and $6 \%$ of white $(p=0.03)$. 
Table 1 Characteristics of study participants

\begin{tabular}{|c|c|c|c|c|c|c|c|c|c|c|c|}
\hline & \multicolumn{2}{|c|}{ Total } & \multicolumn{2}{|c|}{ White } & \multicolumn{2}{|c|}{ Black } & \multicolumn{2}{|c|}{ Latinx } & \multicolumn{2}{|c|}{$\begin{array}{l}\text { Another } \\
\text { race }\end{array}$} & \multirow[t]{2}{*}{$P$-value } \\
\hline & $N$ & $\%$ & $N$ & $\%$ & $N$ & $\%$ & $N$ & $\%$ & $N$ & $\%$ & \\
\hline \multicolumn{12}{|l|}{ Age } \\
\hline $70-74$ & 243 & 36 & 128 & 36.8 & 52 & 30.5 & 30 & 35.6 & 26 & 38.8 & 0.03 \\
\hline $75-79$ & 193 & 26.1 & 89 & 21.5 & 55 & 28.4 & 30 & 38.4 & 15 & 21.9 & \\
\hline $80-84$ & 124 & 17.4 & 58 & 14.5 & 33 & 19.2 & 14 & 13.3 & 16 & 27.9 & \\
\hline $85-89$ & 77 & 14.2 & 51 & 17.7 & 15 & 17.8 & 5 & 8.6 & 5 & 7.6 & \\
\hline $90+$ & 39 & 6.3 & 28 & 9.5 & 5 & 4.1 & 3 & 4.2 & 3 & 3.9 & \\
\hline Mean age & & 78.4 & & 78.8 & & 78.9 & & 77.4 & & 77.7 & \\
\hline Median age & & 76.6 & & 76.7 & & 77.5 & & 76.2 & & 75.5 & \\
\hline 70-79 & & 62.1 & & 58.3 & & 58.9 & & 73.9 & & 60.7 & \\
\hline $80+$ & & 37.9 & & 41.7 & & 41.1 & & 26.1 & & 39.3 & \\
\hline \multicolumn{12}{|l|}{ Race and ethnicity } \\
\hline White & 354 & 45 & & & & & & & & & \\
\hline Black & 160 & 21.3 & & & & & & & & & \\
\hline Latinx & 82 & 20 & & & & & & & & & \\
\hline Another Race & 65 & 13.8 & & & & & & & & & \\
\hline \multicolumn{12}{|l|}{ Gender } \\
\hline Male & 202 & 40 & 119 & 43.7 & 40 & 34.9 & 21 & 36.1 & 18 & 35.6 & 0.47 \\
\hline Female & 470 & 60 & 233 & 56.3 & 120 & 65.1 & 61 & 63.9 & 46 & 64.4 & \\
\hline \multicolumn{12}{|l|}{ Borough } \\
\hline Bronx & 108 & 13.9 & 27 & 7.5 & 43 & 17.9 & 27 & 28.4 & 7 & 7.6 & \\
\hline Brooklyn & 160 & 28.2 & 76 & 24.9 & 55 & 47.2 & 12 & 20 & 13 & 20.5 & \\
\hline Manhattan & 203 & 22.6 & 133 & 29.7 & 31 & 12.3 & 23 & 26 & 14 & 14.6 & \\
\hline Queens & 165 & 28.8 & 86 & 25.9 & 31 & 22.6 & 19 & 24.8 & 26 & 50.7 & \\
\hline Staten Island & 40 & 6.5 & 32 & 12 & 0 & & 1 & 0.8 & 5 & 6.6 & \\
\hline \multicolumn{12}{|l|}{ Marital status } \\
\hline Married or living together & 196 & 43.9 & 113 & 44.3 & 32 & 36.4 & 26 & 43 & 19 & 48.5 & 0.14 \\
\hline Divorced & 117 & 15.1 & 53 & 13.7 & 33 & 17.9 & 15 & 17.3 & 12 & 13.8 & \\
\hline Widowed & 210 & 22.6 & 108 & 23.4 & 55 & 26.1 & 21 & 18.4 & 24 & 24.7 & \\
\hline Separated & 19 & 2.6 & 3 & 0.6 & 7 & 3.5 & 6 & 6.7 & 1 & 0.9 & \\
\hline Never married & 132 & 15.7 & 76 & 18 & 33 & 16.2 & 13 & 14.6 & 9 & 12.1 & \\
\hline \multicolumn{12}{|l|}{ Household income } \\
\hline Less than $\$ 25 \mathrm{k}$ & 177 & 35.3 & 53 & 18.3 & 53 & 33.9 & 44 & 64.4 & 22 & 45.8 & $<0.0001$ \\
\hline$\$ 25 \mathrm{k}$ to less than $\$ 50 \mathrm{k}$ & 151 & 28.5 & 78 & 29.9 & 45 & 38.1 & 14 & 21.5 & 12 & 19.9 & \\
\hline$\$ 50 \mathrm{k}$ to less than $\$ 100 \mathrm{k}$ & 130 & 21.5 & 79 & 26 & 28 & 21.3 & 9 & 12 & 11 & 22.5 & \\
\hline More than $\$ 100 \mathrm{k}$ & 84 & 14.6 & 70 & 25.8 & 7 & 6.6 & 2 & 2.1 & 5 & 11.8 & \\
\hline \multicolumn{12}{|l|}{ Co-existing health conditions } \\
\hline None & 94 & 15.5 & 54 & 16.7 & 16 & 10.9 & 9 & 11.4 & 12 & 21.3 & 0.44 \\
\hline One & 137 & 21.2 & 77 & 19.9 & 31 & 20.1 & 16 & 27.7 & 11 & 21.2 & \\
\hline Two or more & 445 & 63.3 & 223 & 63.5 & 113 & 69 & 57 & 60.9 & 42 & 57.5 & \\
\hline \multicolumn{12}{|l|}{ Immigration status } \\
\hline Born in another country & 204 & 47.7 & 56 & 27.4 & 58 & 53.8 & 48 & 69.9 & 39 & 75.7 & $<0.0001$ \\
\hline Born in the US & 472 & 52.3 & 298 & 72.6 & 102 & 46.2 & 34 & 30.1 & 26 & 24.3 & \\
\hline \multicolumn{12}{|l|}{ Education } \\
\hline Less than high school & 46 & 9.3 & 4 & 2.2 & 16 & 11 & 23 & 27.5 & 3 & 5.2 & $<0.0001$ \\
\hline High school diploma/GED & 173 & 28.5 & 66 & 22.4 & 58 & 31.2 & 27 & 35.6 & 18 & 33.5 & \\
\hline Some college/University & 116 & 17.3 & 61 & 16.6 & 26 & 18.7 & 19 & 22.2 & 8 & 10.4 & \\
\hline College/University degree & 335 & 44.9 & 221 & 58.7 & 59 & 39.1 & 12 & 14.7 & 34 & 51 & \\
\hline \multicolumn{12}{|l|}{ General health rating } \\
\hline Excellent & 67 & 9.3 & 39 & 10.3 & 12 & 7.1 & 7 & 8.9 & 8 & 11.4 & 0.53 \\
\hline
\end{tabular}


Table 1 (continued)

\begin{tabular}{|c|c|c|c|c|c|c|c|c|c|c|c|}
\hline & \multicolumn{2}{|c|}{ Total } & \multicolumn{2}{|c|}{ White } & \multicolumn{2}{|c|}{ Black } & \multicolumn{2}{|c|}{ Latinx } & \multicolumn{2}{|c|}{$\begin{array}{l}\text { Another } \\
\text { race }\end{array}$} & \multirow[t]{2}{*}{$P$-value } \\
\hline & $N$ & $\%$ & $N$ & $\%$ & $N$ & $\%$ & $N$ & $\%$ & $N$ & $\%$ & \\
\hline Very Good & 193 & 28.5 & 116 & 30.4 & 43 & 31.6 & 16 & 22.6 & 13 & 24.2 & \\
\hline Good & 245 & 38.3 & 125 & 37.9 & 60 & 37.3 & 26 & 36.4 & 26 & 41.6 & \\
\hline Fair & 129 & 18.4 & 63 & 18.5 & 33 & 17.7 & 23 & 23.7 & 9 & 13.2 & \\
\hline Poor & 39 & 5.5 & 9 & 2.8 & 12 & 6.4 & 10 & 8.4 & 8 & 9.6 & \\
\hline \multicolumn{12}{|c|}{ Multi-generational household } \\
\hline Yes & 128 & 38.4 & 32 & 24 & 50 & 56.3 & 25 & 43.7 & 21 & 51.6 & $<0.01$ \\
\hline No & 180 & 61.6 & 106 & 76 & 27 & 43.7 & 25 & 56.3 & 15 & 48.4 & \\
\hline \multicolumn{12}{|l|}{ Employment status } \\
\hline Currently working & 77 & 10.1 & 53 & 13.2 & 8 & 5.6 & 7 & 7.1 & 7 & 12.2 & 0.1642 \\
\hline Not currently working & 596 & 89.9 & 298 & 86.8 & 152 & 94.4 & 75 & 92.9 & 58 & 87.8 & \\
\hline
\end{tabular}

Table 2 Experiences of COVID-19 among older New Yorkers

\begin{tabular}{|c|c|c|c|c|c|c|c|c|c|c|c|}
\hline & \multicolumn{2}{|c|}{ Total } & \multicolumn{2}{|c|}{ White } & \multicolumn{2}{|c|}{ Black } & \multicolumn{2}{|c|}{ Latinx } & \multicolumn{2}{|c|}{$\begin{array}{l}\text { Another } \\
\text { race }\end{array}$} & \multirow[t]{2}{*}{$P$-value } \\
\hline & $N$ & $\%$ & $N$ & $\%$ & $N$ & $\%$ & $N$ & $\%$ & $N$ & $\%$ & \\
\hline \multicolumn{12}{|l|}{ Have you ever been tested for coronavirus? } \\
\hline Yes & 410 & 62.6 & 204 & 58.4 & 99 & 63 & 61 & 73 & 36 & 57.8 & 0.13 \\
\hline No & 265 & 37.4 & 150 & 41.6 & 61 & 37 & 21 & 27 & 28 & 42.2 & \\
\hline \multicolumn{12}{|c|}{ Have you ever had a COVID-19 test that was positive? } \\
\hline Yes & 45 & 12.4 & 14 & 8 & 10 & 7.4 & 16 & 24.2 & 5 & 17.1 & $<0.01$ \\
\hline No & 365 & 87.6 & 190 & 92 & 89 & 92.6 & 45 & 75.8 & 31 & 82.9 & \\
\hline \multicolumn{12}{|c|}{ How many people do you personally know who have tested positive? } \\
\hline 0 & 224 & 37.1 & 109 & 31.3 & 50 & 36.6 & 37 & 47.7 & 21 & 42.1 & 0.05 \\
\hline $1-2$ & 160 & 25.8 & 85 & 26.8 & 45 & 34.5 & 13 & 15.3 & 16 & 30.1 & \\
\hline $3-4$ & 90 & 14.7 & 59 & 19.1 & 15 & 10.5 & 10 & 13.8 & 4 & 5.6 & \\
\hline 5 or more & 138 & 22.5 & 77 & 22.7 & 29 & 18.4 & 15 & 23.2 & 14 & 22.2 & \\
\hline \multicolumn{12}{|c|}{ How many people do you personally know that have died from COVID? } \\
\hline 0 & 330 & 50.2 & 193 & 54.5 & 67 & 49.2 & 32 & 42.6 & 30 & 46.8 & 0.03 \\
\hline $1-2$ & 184 & 28.6 & 105 & 31.4 & 41 & 26.8 & 22 & 29.2 & 13 & 16.7 & \\
\hline $3-4$ & 66 & 10.5 & 31 & 8.6 & 18 & 10.7 & 10 & 13.9 & 6 & 14.1 & \\
\hline 5 or more & 59 & 10.7 & 17 & 5.5 & 22 & 13.4 & 10 & 14.4 & 10 & 22.4 & \\
\hline \multicolumn{12}{|l|}{ Computer access } \\
\hline Owns a computer or mobile device & 527 & 77.6 & 298 & 83.7 & 121 & 77.7 & 50 & 67.8 & 46 & 71.4 & 0.03 \\
\hline Does not own a computer or mobile device & 141 & 22.4 & 55 & 16.3 & 38 & 22.3 & 29 & 32.2 & 16 & 28.6 & \\
\hline \multicolumn{12}{|l|}{ Internet access } \\
\hline Has internet access & 486 & 77.7 & 278 & 84.3 & 114 & 75.6 & 47 & 73.7 & 37 & 63.7 & 0.01 \\
\hline No internet access & 133 & 22.3 & 53 & 15.7 & 38 & 24.4 & 23 & 26.3 & 17 & 36.3 & \\
\hline \multicolumn{12}{|c|}{ Telehealth appointment with a doctor or nurse within the past 3 months } \\
\hline Yes & 285 & 44.3 & 128 & 35.3 & 78 & 53.8 & 40 & 50.6 & 32 & 44.9 & 0.01 \\
\hline No & 389 & 55.7 & 224 & 64.7 & 82 & 46.2 & 42 & 49.4 & 33 & 55.1 & \\
\hline \multicolumn{12}{|c|}{ Since COVID started have you received food from a food pantry? } \\
\hline Yes & 205 & 30.8 & 62 & 17.6 & 77 & 42.5 & 37 & 43.1 & 24 & 34.8 & $<0.0001$ \\
\hline No & 469 & 69.2 & 292 & 82.4 & 83 & 57.5 & 45 & 56.9 & 39 & 65.2 & \\
\hline
\end{tabular}

Overall, 78 percent of respondents had computer and internet access at home. Both computer and internet access varied by race and ethnicity. Eighty-four percent of white respondents reported owning a computer or mobile device, 
whereas only $68 \%$ of Latinx respondents, $71 \%$ of Blacks and $78 \%$ of those of another race $(p=0.03)$. Regarding internet access, $84 \%$ of whites have internet access compared to $76 \%$ of Black and $74 \%$ of Latinx respondent and $64 \%$ of those of another race and ethnicity $(p=0.01)$. Forty-four percent of respondents reported an appointment with a health care provider in the past 3 months by video or phone. Among whites, $35 \%$ of respondents reported a telehealth appointment in the past 3 months. In contrast, $45 \%$ of those of another race, $51 \%$ of Latinx and 54\% of Blacks reported a telehealth appointment $(p=0.01)$.

\section{Effects of COVID-19}

Sixty-three percent of respondents reported that COVID-19 affected their life in a negative way, either "somewhat" or "a lot". Additionally, 58\% reported not seeing friends or family in person and $68 \%$ reported interacting "a lot less" with people outside of their home (Table 3). Fifty-four percent reported thinking "a lot" or "somewhat" about themselves or someone else dying from COVID-19, and 53\% reported worrying about someone who was diagnosed with COVID19 in the last 3 months. This effect varied by race and ethnicity, with $39 \%$ of white respondents reporting that COVID-19 affected their life in a negative way "a lot" compared to $28 \%$ of Black, 25\% of Latinx and 21\% of respondents of another race $(p<0.01)$.

With regards to household finances, $18 \%$ reported the COVID-19 pandemic had created "some financial problems" for them, and 13\% reported "significant financial problems". Two percent of white respondents reported "sometimes not enough food to eat" or "often not enough to eat" compared to $8 \%$ of Black respondents, $12 \%$ of Latinx respondents and $18 \%$ of those of another race $(p<0.001)$. Overall, $8 \%$ or respondents reported sometimes or often not having enough to eat, with $31 \%$ reporting receipt of food from a food pantry, community organization or a government program during COVID-19 pandemic. Forty-three percent of Black and 43\% of Latinx respondents reported using a food pantry during COVID-19 pandemic, compared to $35 \%$ of respondents of another race and ethnicity and $18 \%$ of whites $(p<0.01)$.

Overall, $15 \%$ of respondents reported prior history of anxiety and $19 \%$ history of depression. As for the effects of COVID-19 pandemic on mental health, $18 \%$ of respondents screened positive for depression and $17 \%$ for anxiety. Twenty-nine percent of Latinx respondents screened for depression compared to $15 \%$ among all other races $(p=0.04)$. There was no significant difference in reporting of anxiety by race and ethnicity.

\section{Discussion}

The findings from the SILVER Study are among the first to describe the experiences and effects of the COVID-19 pandemic on older adults living in their homes, offering a glimpse of the challenges faced by this population as they navigated the COVID-19 pandemic. In our study, respondents reported financial hardship, isolation, depression and anxiety and limited access to Internet and telehealth.

Our results are consistent with previously noted racial and ethnic inequities. [12-14] Two studies examined hospitalizations and death among older New Yorkers $[14,15]$ and others assessed structural causes of racial inequities. [13, 16-19] A study that involved a weekly telephone survey of New Yorkers aged 18 and older looked at issues such as food security, employment and mental health. [12] Two articles $[15,18]$ about COVID-19 and NYC report those over 65 as two age groups (65-75, and 75), all other articles either do not report an age variable or do no disaggregate over 65 .

Our study showed that older adults in NYC had twice the rate of depression (19\%) in 2020-2021 compared to the 2017 New York City Community Health Survey estimate (9\%) [7]. This is consistent with what has been reported in another study among older adults in the US, which noted increased loneliness, depression and anxiety compared to the pre-pandemic period. [20] However, compared to younger age groups, the effects of the COVID-19 pandemic in terms of negative mental health consequences has generally been noted to a lesser degree among older adults. [21-24] While this finding might be surprising, it is possible that the resilience and coping skills built over a lifetime might be the reason why older individuals reported less mental health impacts from the pandemic.

The SILVER study found differences in experiences and effects of COVID-19 pandemic by racial and ethnic groups. White respondents, who had higher income and higher educational attainment compared to other racial and ethnic groups, were more likely to report a negative impact of COVID-19 on their lives compared to other racial and ethnic groups. Latinx respondents, on the other hand, while less likely to report negative effects of COVID-19 on their lives, were most likely to have tested for SARS-CoV-2 and have a positive test. They also reported higher rates of depression. Receiving food from a food pantry also varied by race and ethnicity, with over twice as many Black and Latinx respondents reporting receipt since start of the pandemic compared to white respondents. A phone survey conducted by the NYC Department of Mental Health and Hygiene also found use of food services differed by race and ethnicity, with Black New Yorkers being the racial/ethnic group with the highest report as of March 2021 [25]. 


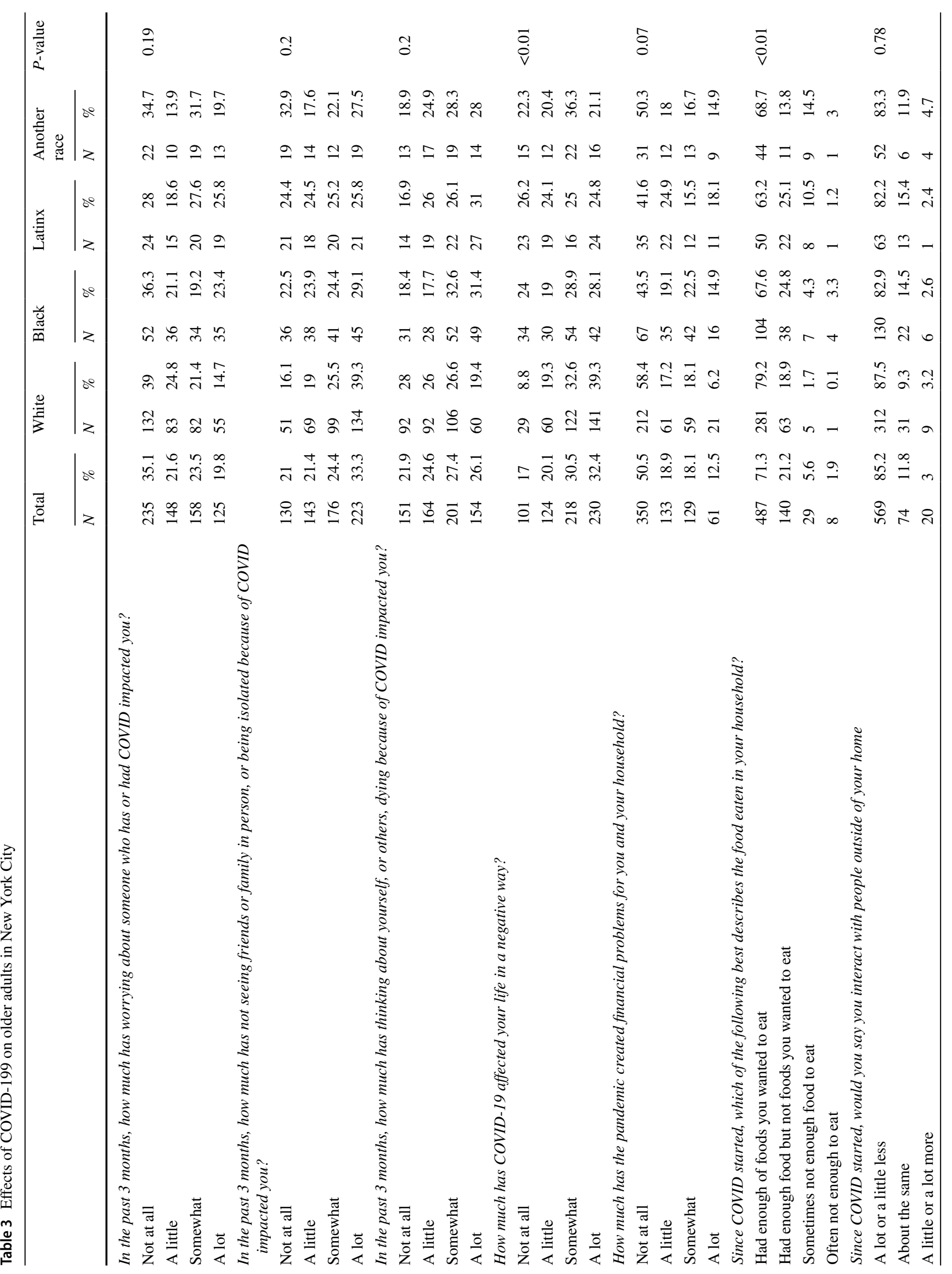




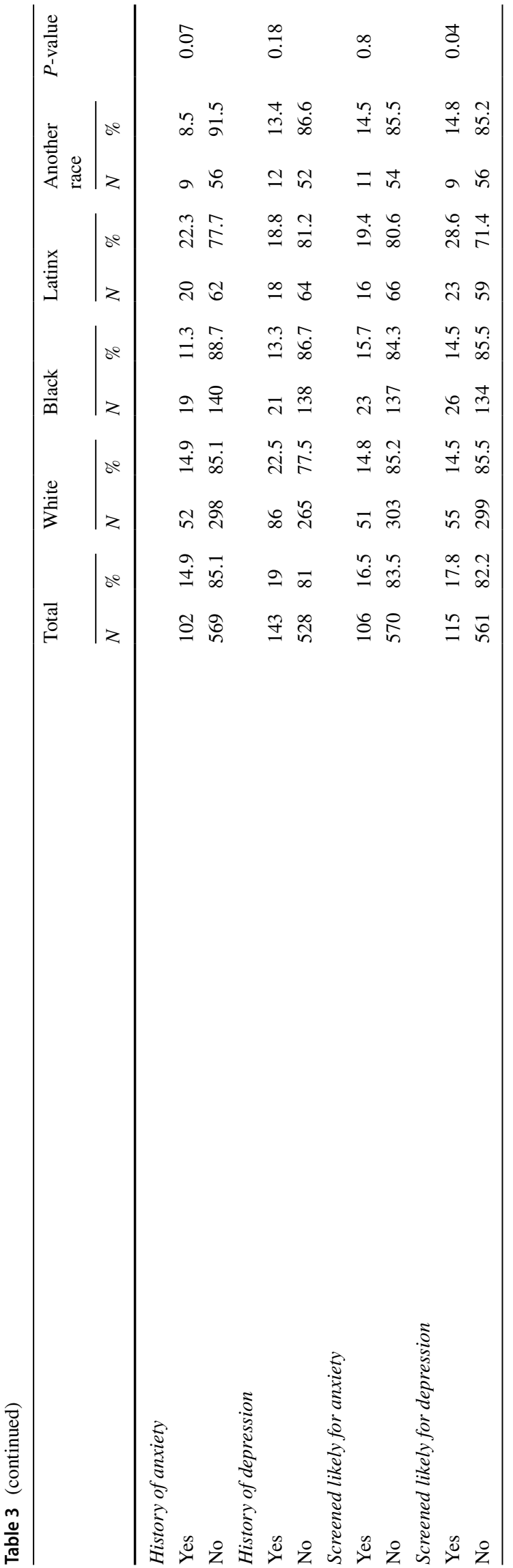

The use of telehealth expanded greatly during COVID19 pandemic as a result of concerns about visiting health facilities and the movement constraints imposed as part of effort to control SARS-CoV-2 transmission. [26-28] Multiple studies identified telehealth use inequities by race and ethnicity, with Black patients in NYC accessing a hospital system via telehealth less often compared to their white counterparts. [26] However, among our respondents, whites (35\%) were the least likely to use telehealth, whereas over half of Latinx and Black respondents reported its use.

\section{Limitations}

The study has strengths and limitations. The use of random-number dial sampling offered the opportunity to identify a random sample of respondents for this study, and calling landlines facilitated contact with older individuals. Efforts were made to conduct the surveys in several languages, representing the most common languages used by NYC residents. Another strength is that the size of the sample of older individuals recruited allowed us to look at outcomes amongst subsets of this population. A limitation of the study is that we had underrepresentation of Asians in the sample, with this group representing about $12 \%$ of the older adult population in NYC but only $3 \%$ of our respondents. In addition, although landlines were intentionally chosen over cell phones so that a more representative sample of older adults could be reached, there may be coverage error as adults who do not have a landline may be different from those who do. Finally, in our study, race and ethnicity was a crude but feasible proxy for the complex impact of structural racism on health. We acknowledge differences in racial groups are driven by societal differences rather than biological or cultural differences.

This study assessed the burden of COVID-19 and the effects of the pandemic on adults over 70 years of age living at home in NYC. The findings provide insight into the different experiences of older adults, which in turn should inform policy and programmatic decisions to respond to their needs and highlight areas for further study. The NYC Department of Health and Mental Hygiene's recent declaration of racism as a public health crisis [29] and the directives associated with the resolution will take aim at the policies and programs rooted in systemic racism. Specific suggestions based on our study include making internet connectivity a public utility, creating guidelines for organizations to safely care for homebound older adults so that key services are not interrupted during a similar crisis, and reducing isolation and loneliness that results from confinement. [30] 
Author Contributions WES, MR, ARG, AL, SF, DH conceived of the study. ARG, MR supervised the study. Data analysis was led by MM with input from SF, ARG and KC. The manuscript was drafted by ARG. All coauthors reviewed the manuscript and provided input.

Funding The survey was supported by the New York Community Trust, the Samuels Foundation, and an anonymous donor.

Data Availability The datasets generated during and/or analyzed during the current study are available from the corresponding author on reasonable request.

Code Availability The code, created in the statistical program SAS, is available from the corresponding author on reasonable request.

\section{Declarations}

Conflict of interest The authors have no competing interests to declare that are relevant to the content of this article.

Ethical Approval The Columbia University Irving Medical Center and Research Triangle Institute institutional review boards approved the protocol and data collection tools.

Consent to Participate Interviewers read a verbal consent over the phone to participants.

Consent for Publication Not applicable.

\section{References}

1. COVID-19 Risks and Vaccine Information for Older Adults. (2021, August 2). Centers for Disease Control and Prevention Retrieved September 9 from https://www.cdc.gov/coronavirus/ 2019-ncov/need-extra-precautions/older-adults.html

2. De Pue, S., Gillebert, C., Dierckx, E., Vanderhasselt, M. A., De Raedt, R., \& Van den Bussche, E. (2021). The impact of the COVID-19 pandemic on wellbeing and cognitive functioning of older adults. Scientific Reports, 11(1), 4636. https://doi.org/10. 1038/s41598-021-84127-7

3. Health care considerations for older people during COVID-19 pandemic. (2021). https://www.euro.who.int/en/health-topics/ health-emergencies/coronavirus-covid-19/publications-and-techn ical-guidance/vulnerable-populations/health-care-considerationsfor-older-people-during-covid-19-pandemic

4. Policy Brief: The Impact of COVID-19 on older persons. (2020). https://unsdg.un.org/sites/default/files/2020-05/Policy-Brief-TheImpact-of-COVID-19-on-Older-Persons.pdf

5. Hashan, M. R., Smoll, N., King, C., Ockenden-Muldoon, H., Walker, J., Wattiaux, A., Graham, J., Booy, R., \& Khandaker, G. (2021). Epidemiology and clinical features of COVID-19 outbreaks in aged care facilities: A systematic review and meta-analysis. EClinicalMedicine, 33, 100771. https://doi.org/10.1016/j. eclinm.2021.100771

6. Valenzuela, P. L., Santos-Lozano, A., Lista, S., Serra-Rexach, J. A., Emanuele, E., \& Lucia, A. (2020). Coronavirus lockdown: Forced inactivity for the oldest old? Journal of the American Medical Directors Association, 21(7), 988-989. https://doi.org/ 10.1016/j.jamda.2020.03.026
7. Greer S, A. L., Toprani, A., Hinterland, K., Dongchung, T. Y., Brahmbhatt, D., Miranda, T., Guan, Q. X., Kaye, K., \& Gould, L. H. (2019). Health of Older Adults in New York City. https:// www1.nyc.gov/assets/doh/downloads/pdf/episrv/2019-olderadult-health.pdf

8. Tai, D. B. G., Sia, I. G., Doubeni, C. A., \& Wieland, M. L. (2021). Disproportionate impact of COVID-19 on racial and ethnic minority groups in the United States: a 2021 update. Journal of Racial Ethnical Health Disparities. https://doi.org/10.1007/ s40615-021-01170-w

9. Health Equity Considerations and Racial and Ethnic Minority Groups. (2021, April 19). Centers for Disease Control and Prevention Retrieved Nov 15 from https://www.cdc.gov/coronavirus/ 2019-ncov/community/health-equity/race-ethnicity.html

10. Kroenke, K., Spitzer, R. L., \& Williams, J. B. (2003). The Patient Health Questionnaire-2: validity of a two-item depression screener. Medical Care, 41(11), 1284-1292. https://doi.org/10. 1097/01.MLR.0000093487.78664.3C

11. Kroenke, K., Spitzer, R. L., Williams, J. B., Monahan, P. O., \& Lowe, B. (2007). Anxiety disorders in primary care: Prevalence, impairment, comorbidity, and detection. Annals of Internal Medicine, 146(5), 317-325. https://doi.org/10.7326/0003-4819-146-5200703060-00004

12. El-Mohandes, A., Ratzan, S. C., Rauh, L., Ngo, V., Rabin, K., Kimball, S., Aaron, B., \& Freudenberg, N. (2020). COVID-19: A barometer for social justice in New York City. American Journal of Public Health, 110(11), 1656-1658. https://doi.org/10.2105/ AJPH.2020.305939

13. Mountantonakis, S. E., Epstein, L. M., Coleman, K., Martinez, J., Saleh, M., Kvasnovsky, C., Brown, R. M., McCulloch, E., Kuvin, J., Richardson, S., Makker, P., Lesser, M., Mieres, J. H., Davidson, K. W., Roswell, R. O., \& Northwell, C.-R.C. (2021). The association of structural inequities and race with out-of-hospital sudden death during the COVID-19 pandemic. Circulation Arrhythmia and Electrophysiology, 14(5), e009646. https://doi.org/10.1161/ CIRCEP.120.009646

14. Wadhera, R. K., Wadhera, P., Gaba, P., Figueroa, J. F., Joynt Maddox, K. E., Yeh, R. W., \& Shen, C. (2020). Variation in COVID19 hospitalizations and deaths across New York City boroughs. JAMA, 323(21), 2192-2195. https://doi.org/10.1001/jama.2020. 7197

15. Ogedegbe, G., Ravenell, J., Adhikari, S., Butler, M., Cook, T., Francois, F., Iturrate, E., Jean-Louis, G., Jones, S. A., Onakomaiya, D., Petrilli, C. M., Pulgarin, C., Regan, S., Reynolds, H., Seixas, A., Volpicelli, F. M., \& Horwitz, L. I. (2020). Assessment of racial/ethnic disparities in hospitalization and mortality in patients with COVID-19 in New York City. JAMA Network Open, 3(12), e2026881. https://doi.org/10.1001/jamanetworkopen.2020. 26881

16. Douglas, J. A., \& Subica, A. M. (2020). COVID-19 treatment resource disparities and social disadvantage in New York City. Preventive Medicine, 141, 106282. https://doi.org/10.1016/j. ypmed.2020.106282

17. Fu, X., \& Zhai, W. (2021). Examining the spatial and temporal relationship between social vulnerability and stay-at-home behaviors in New York City during the COVID-19 pandemic. Sustain Cities Soc, 67, 102757. https://doi.org/10.1016/j.scs.2021.102757

18. Kim, B., Rundle, A. G., Goodwin, A. T. S., Morrison, C. N., Branas, C. C., El-Sadr, W., \& Duncan, D. T. (2021). COVID-19 testing, case, and death rates and spatial socio-demographics in New York City: An ecological analysis as of June 2020. Health Place, 68, 102539. https://doi.org/10.1016/j.healthplace.2021. 102539

19. Zhang, Y., Khullar, D., Wang, F., Steel, P., Wu, Y., Orlander, D., Weiner, M., \& Kaushal, R. (2021). Socioeconomic variation in characteristics, outcomes, and healthcare utilization of COVID-19 
patients in New York City. PLoS One, 16(7), e0255171. https:// doi.org/10.1371/journal.pone.0255171

20. Krendl, A. C., \& Perry, B. L. (2021). The impact of sheltering in place during the COVID-19 pandemic on older adults' social and mental well-being. The Journals of Gerontology: Series B, 76(2), e53-e58. https://doi.org/10.1093/geronb/gbaa110

21. Bruine de Bruin, W. (2021). Age differences in COVID-19 risk perceptions and mental health: evidence from a National US survey conducted in March 2020. The Journals of Gerontology: Series B. https://doi.org/10.1093/geronb/gbaa074

22. Czeisler, M. É., Lane, R. I., Petrosky, E., Wiley, J. F. 1., Aleta, C., \& Rajaratnam, S. M. W. (2020). Mental Health, Substance Use, and Suicidal Ideation During the COVID-19 Pandemic — United States, June 24-30, 2020. Morbidity and Mortality Weekly Report, 69.

23. Pearman, A., Hughes, M. L., Smith, E. L., \& Neupert, S. D. (2021). Age differences in risk and resilience factors in COVID19-related stress. The Journals of Gerontology: Series B, 76(2), e38-e44. https://doi.org/10.1093/geronb/gbaa120

24. Vahia, I. V., Jeste, D. V., \& Reynolds, C. F., 3rd. (2020). Older adults and the mental health effects of COVID-19. JAMA, 324(22), 2253-2254. https://doi.org/10.1001/jama.2020.21753

25. Crossa, A., Baquero, M., Etheredge, A. J., Seidl, L., Nieves, C., Dannefer, R., Solomon, E., Prasad, D., Jasek, J., Dongchung, T. Y, Marder, T., Deng, W. Q., Amber Levanon Seligson, \& Dumas, S. E. (2021). Food insecurity and access in New York City during the COVID-19 pandemic, 2020. 10.
26. Chunara, R., Zhao, Y., Chen, J., Lawrence, K., Testa, P. A., Nov, O., \& Mann, D. M. (2021). Telemedicine and healthcare disparities: A cohort study in a large healthcare system in New York City during COVID-19. Journal of the American Medical Informatics Association, 28(1), 33-41. https://doi.org/10.1093/jamia/ocaa217

27. Doraiswamy, S., Abraham, A., Mamtani, R., \& Cheema, S. (2020). Use of telehealth during the COVID-19 pandemic: Scoping review. Journal of Medical Internet Research, 22(12), e24087. https://doi.org/10.2196/24087

28. Koonin, L. M., Hoots, B., Tsang, C. A., Leroy, Z., Farris, K., Jolly, T., Antall, P., McCabe, B., Zelis, C. B. R., Tong, I., \& Harris, A. M. (2020). Trends in the use of telehealth during the emergence of the COVID-19 pandemic - United States. Morbidity and Mortality Weekly Report, 69(43), 1595-1599. https://doi.org/10.15585/ mmwr.mm6943a3

29. Zraick, K. (2021, October 19). Racism Is Declared a Public Health Crisis in New York City. New York Times. https://www.nytimes. com/2021/10/19/nyregion/nyc-racism-healthcare-system.html

30. Fried, L. P. (2021). The need to invest in a public health system for older adults and longer lives, fit for the next pandemic. Frontiers in Public Health, 9, 682949. https://doi.org/10.3389/fpubh.2021. 682949

Publisher's Note Springer Nature remains neutral with regard to jurisdictional claims in published maps and institutional affiliations. 